\title{
Effects of Drugstore Experience Factors on Customers' Satisfaction with their Shop-Visit Experience
}

\author{
Sangeun Lee \\ Department of Beauty Arts, Suwon Women's University, Suwon-si, Gyeonggi-do, Korea
}

Corresponding author: Sangeun Lee, Department of Beauty Arts, Suwon Women's University, 72 Onjeong-ro, Gwonseon-gu, Suwon-si, Gyeonggi-do 16632, Korea

Tel.: +82 312908374

Email: make-up1004@swc.ac.kr

Received January 24, 2018

Revised March 21, 2018

Accepted April 23, 2018

Published June 30, 2018

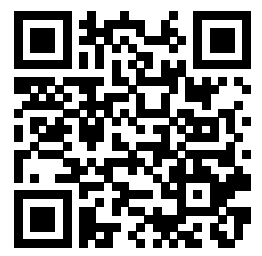

\begin{abstract}
Purpose: This study investigated the effects of drugstore experience factors on customers' satisfaction with shop-visit experience, with regard to the environmental stimuli provided by a Korean drugstore, which reflects the changing state of the beauty market. Methods: Convenience sampling was conducted with women in their 20s who had visited drugstores. Cronbach's $\alpha$ coefficient determined the reliability of their satisfaction. Furthermore, correlation analysis and multiple regression analysis were conducted to investigate the influence of drugstore experience factors on customers' satisfaction with shop-visit experience. Results: Regarding the correlation between the drugstore experience factors and customers' satisfaction with their shop-visit experience, the following factors can be ranked in the order of a high correlation: brand act, think, sense, relate, and feel. It was found that the higher the brand act factor, brand sense factor, brand relate factor, and brand think factor, the higher was the customers' satisfaction level of shopvisit experience. Conclusion: The results of this study suggest that the drugstore experience factors affect customers' satisfaction with their visits to drugstores and the overall experience factors are important factors in satisfaction. Particularly, act factors had the greatest influence on customers' satisfaction with their shop-visit experience, which suggests that direct consumer experience would have a greater influence on their purchasing act.
\end{abstract}

Keywords: Experience factor, Drugstore, Cosmetics, Satisfaction, Experience marketing

\section{Introduction}

드럭스토어는 화장품, 약국, 편의점을 결합한 매장이라고 할 수 있는데 미용과 건강에 관련된 제품을 모두 판매하는 복합적인 형태의 점포이다. 또한 드럭스토어는 전반적으로 소비자의 편리 를 위한 self-selection 형식으로 효율성과 자율성을 구현하며, 매장 내 카운슬러를 운용하여 고객문의에 전문적으로 응대하는 방식을 사용한다. 특히 트랜드에 민감하게 반응하며 유행하는 인 기상품들을 직접 사용해 보고 평가하길 원하는 소비자들을 충족 시킨다(Lee \& Han, 2013).

국내에서 드럭스토어는 약사법 구제를 위해 의약품의 소매점 판매 금지로 건강, 미용용품 위주의 반쪽 드럭스토어 형태의 '한 국형 드럭스토어'로 진화 하였다(Lee, 2016a). 현재 국내 드럭
스토어는 대부분 대기업에 의한 CJ 올리브영, GS 왓슨즈, 코오 롱 $\mathrm{W}-\mathrm{Store}$, 롯데 롭스, 신세계 분스, 농심 판도라 등이 대표적 이며 새로운 성장 동력 확보에 주력하고 있다. 그러나 짧은 역사 적 배경과 화장품 브랜드 전문숍과의 차별화된 브랜드 이미지 및 인지도 확보 미흡으로 인하여 국내 실정에 맞는 드럭스토어의 형 태를 갖추지 못하고 있다(Lee, 2016b), 특히 드럭스토어를 단순 잡화점이 아닌 토탈·뷰티스토어 전문숍으로 인식하지 못한 실정 이다. 이에 한국형 드럭스토어의 차별화 전략으로 구매심리를 자 극하여 소비자들에게 '쇼핑'은 단순히 물건을 구매하는 행위를 넘 어 소비 자체를 자신의 독특한 체험과 개성으로 인식하도록 하 는 것이 목적이다. 특히 선택적 소비의 비중이 높아지면서 제품 의 특징이나 기능중심의 전통적 마케팅에서 제품 브랜드와의 정 신적 자극과 교감, 교류를 가질 수 있도록 하는 체험적 마케팅으 
로 변화되고 있다(Park, 2014). 화장품의 경우 일반 생활용품과 는 달리 소비자가 선호하는 바가 뚜렷하기 때문에 제품을 알리고 유지하기 위해 차별화된 전략이 중요하다고 많은 업계 관계자들 은 말하고 있다(Cho et al., 2015).

체험이란 자극에 대한 반응으로 제품을 직접 관찰하고 경험 하는 것을 의미하며 그 중요성이 부각되고 있다. 소비자들은 이 제 기능적 특징이나 제품의 품질을 넘어 그 이상의 것을 기대하 고 있으며, 그들의 감각을 자극하는 제품 특징과 커뮤니케이션 마케팅을 원하고 있다(Lee \& Han, 2014). 또한 체험은 단순히 구경하는 것이 아니고 참여하는 것, 몸소 경험하는 것을 의미하 며, 실제로 보고, 듣고, 겪는 일 또는 그 과정에서 얻어지는 지식 이나 기능을 총체적으로 나타내는 용어이다(Yang \& Jo, 2016). 따라서 체험 요인은 소비자들이 드럭스토어를 인식하고 만족도 를 형성하는데 총체적 역할을 할 수 있으며 소비자로 하여금 브 랜드 신뢰와 확신으로 제품구매를 위한 소비를 하게 만든다. 이 는 제품을 구매하고 평가하는 과정에서 제품 자체에 대한 기본적 인 품질뿐만 아니라 소비자가 지각할 수 있는 경험적 체험 요인 의 요소가 함께 반영되어야 함을 시사한다. 이처럼 체험 요인 마 케팅의 중요성을 인식하고 꾸준히 연구되어 왔으며 연구자들마 다 다양한 연구결과를 제시하고 있다.

이제까지의 드럭스토어에 관한 선행연구(Kim et al., 2015; Lee \& Han, 2014; Lee, 2016a; Park \& Chung, 2015)를 보 면 드럭스토어의 공간구성, 라이프 스타일, 분위기 등의 영향관 계에 관한 실증 연구가 활발히 진행되고 있다. 그러나 체험요인 에 반응하는 주된 소비집단이 매장방문경험의 변수에 어떤 영향 을 미칠 수 있는지에 대한 연구, 특히 한국형 드럭스토어의 매장 형태와 같이 특화된 전문점을 대상으로 하는 국내 연구들은 미비 한 실정이다. 따라서 변화되고 있는 뷰티시장의 형태를 반영한 드럭스토어가 제공하는 환경적 자극에 대해 실무적 체험요인의 전략을 제시하고자 한다.

이에 본 연구는 5 가지 체험요인과 매장 방문 경험에 대한 만족 도 영향 요인을 알아보고 이를 위해 체험요인을 독립변인으로 설
정하고 매장 방문 경험을 종속변인으로 설정하여 체험요인이 매 장 방문 경험 만족도에 어떠한 영향을 미치며, 각 변인이 어느 정 도의 영향력을 미치는지 인과관계를 실증하고자 한다.

또한 향후 차별화된 드럭스토어 뷰티매장의 다양한 체험 요인 과 유통시장 변화에 맞는 지속적인 연구가 이루어질 수 있도록 주 구매 고객층인 20 대 여성을 대상으로 드럭스토어 매장의 체 험요인이 매장 방문 경험에 미치는 만족도를 분석하여 보다 효율 적인 체험요인 제공의 방향성을 찾고자 한다. 드럭스토어의 관련 연구가 미비한 상황에서 본 연구 결과가 드럭스토어의 발전 방향 과 현실적인 마케팅 전략에 도움이 되고자 한다.

따라서 본 연구는 고객의 진정한 needs를 충족시켜 주고 고객 스스로 자발적인 참여를 유도할 수 있는 체험요소를 통해 체험 마케팅을 효과적으로 활용하여 실무적인 시사점을 제시하고자 한다.

\section{Methods}

\section{1. 연구 대상 및 자료 수집}

본 연구대상의 표집은 2017년 7월 1일부터 7월 15일까지 수 도권 및 경기도 지역에서 드럭스토어에 직접 방문하는 20 대를 대상으로 편의 표집하였다. 총 250 명에게 설문을 배포하여 자기 기입식으로 작성하였으며 이중 불성실한 응답 11 부를 제외하고 239 부가 본 연구의 자료로 사용되었다.

\section{2. 측정항목 및 내용}

본 연구에 사용한 문항은 인구통계학적 특성(5문항), 체험요인 (22문항), 만족도(6문항) 총 33문항으로 구성되었으며, 선행 연 구 (Hwang \& Lee, 2011; Lee, 2016c; Lee, 2016a; Lee \& Han, 2014; Lee \& Hwang, 2010; Yoon \& Lee, 2012)에서 사 용된 측정항목을 수정.보완하였다. 체험요인을 전략적 체험모듈 (strategy experiential modules, SEMs) 5가지 차별적인 유형

Table 1. Configuration of a questionnaire

\begin{tabular}{|c|c|c|c|}
\hline Variables & Scales & No. of questions & Quotation and applied data \\
\hline Demographic features & Nominal scale & 5 & Organization of researchers \\
\hline \multirow{5}{*}{ Experience factor } & \multirow{5}{*}{ 5-point Likert scale } & \multirow{5}{*}{22} & - Lee \& Hwang (2010) \\
\hline & & & - Hwang \& Lee (2011) \\
\hline & & & - Yoon \& Lee (2012) \\
\hline & & & - Lee (2016c) \\
\hline & & & - Lee \& Han (2014) \\
\hline \multirow{3}{*}{ Satisfaction } & \multirow{3}{*}{ 5-point Likert scale } & \multirow{3}{*}{6} & - Lee (2016a). \\
\hline & & & - Kim et al. (2015) \\
\hline & & & - Choi et al. (2013) \\
\hline
\end{tabular}


Table 2. General features

\begin{tabular}{|c|c|c|c|}
\hline Category & & Frequency $(\mathrm{N})$ & Percentage (\%) \\
\hline \multirow{4}{*}{ Age } & 19 years old & 126 & 52.7 \\
\hline & 20 years old & 59 & 24.7 \\
\hline & 21 years old & 21 & 8.8 \\
\hline & 22 years old or more & 33 & 13.8 \\
\hline \multirow{4}{*}{$\begin{array}{l}\text { Frequency of monthly } \\
\text { visits }\end{array}$} & Once a month & 44 & 18.4 \\
\hline & 2-3 times a month & 111 & 46.4 \\
\hline & 4-5 times a month & 54 & 22.6 \\
\hline & 6 times or more a month & 30 & 12.6 \\
\hline \multirow{4}{*}{ Amount spent per visit } & Less than KRW 10,000 & 30 & 12.6 \\
\hline & KRW 10,000-less than KRW 50,000 & 156 & 65.3 \\
\hline & KRW 50,000 -less than KRW 100,000 & 38 & 15.9 \\
\hline & KRW 100,000 or more & 15 & 6.3 \\
\hline \multirow{4}{*}{ Average shopping time } & Less than $10 \mathrm{~min}$ & 46 & 19.2 \\
\hline & 10-less than 30 min & 144 & 60.3 \\
\hline & 30 min-less than $1 \mathrm{~h}$ & 24 & 10.0 \\
\hline & 1h or more & 25 & 10.5 \\
\hline \multirow{7}{*}{$\begin{array}{l}\text { Purchased products } \\
\text { (Multiple responses, } \\
\text { total=646) }\end{array}$} & Basic cosmetics & 68 & 10.5 \\
\hline & Color cosmetics & 208 & 32.2 \\
\hline & BB cream, foundation products & 129 & 20.0 \\
\hline & Skincare products & 94 & 14.6 \\
\hline & Accessories products & 76 & 11.8 \\
\hline & Nail-care products & 68 & 10.5 \\
\hline & Others & 3 & 0.5 \\
\hline Total & & 239 & 100.0 \\
\hline
\end{tabular}

으로 제시하는데 구체적인 체험요인의 내용은 다음과 같다(Suh, 2012). 감각요인은 매장 내 디스플레이, 조명, 향기와 같은 요소 를 포함하여 5 문항으로 구성하였고, 느낌요인은 즐거움, 행복감 등 감정의 5 문항으로 구성 하였다. 인지요인으로는 브랜드에 대 한 관심, 흥미 요소를 포함하여 4 문항으로 구성하였고, 브랜드와 의 관계 요인은 유대감, 특별함, 친근함 등의 4 문항으로 구성하 였으며, 마지막으로 행동요인은 체험 이후 제품 구매행동 등의 내용을 포함하는 4 문항으로 구성하였다. 설문지의 측정항목구성 과 출처는 다음과 같다(Table 1).

\section{3. 자료분석 방법}

본 연구를 수행하기 위한 실증 분석 방법은 다음과 같다.

1) 20 대 여성의 인구통계학적 특성을 알아보기 위하여 빈도분석 (frequency analysis)을 실시하였다.

2) 드럭스토어 체험요인, 매장 방문 경험 만족도의 신뢰도는 Cronbach's $\alpha$ 계수로 판단하였다.
3) 20대 여성의 인구통계학적 특성에 따른 드럭스토어 체험요 인, 매장 방문 경험 만족도의 차이를 알아보기 위하여 일원변량분 석(one-way ANOVA)을 실시하였으며, Scheffe의 다중범위검정 (Scheffe's multiple range test)을 통하여 $p\langle 0.05$ 에서 유의한 차이 를 검정하였다.

4) 20 대 여성의 드럭스토어 체험요인이 매장 방문 경험 만족도에 미치는 영향을 알아보기 위하여 상관분석과 다중회귀분석을 실시 하였다.

본 연구의 실증분석은 모두 유의수준 $5 \%$ 에서 검증하였으며, 통계처리는 SPSSWIN 21.0 프로그램(IBM, USA)을 사용하여 분석하였다.

\section{Results and Discussion}

\section{1. 인구 통계학적 특성}


Table 3. Drugstore experience factors and customers' satisfaction with their shop-visit experience

\begin{tabular}{|c|c|c|c|c|c|c|}
\hline \multicolumn{2}{|l|}{ Category } & $\mathrm{N}$ & Min & Max & Mean & SD \\
\hline \multirow{5}{*}{$\begin{array}{l}\text { Drugstore experience } \\
\text { factors }\end{array}$} & Sense & 239 & 1.00 & 5.00 & 3.52 & 0.69 \\
\hline & Feel & 239 & 1.00 & 5.00 & 3.26 & 0.74 \\
\hline & Think & 239 & 1.00 & 5.00 & 3.53 & 0.72 \\
\hline & Relate & 239 & 1.00 & 5.00 & 3.27 & 0.75 \\
\hline & Act & 239 & 1.00 & 5.00 & 3.50 & 0.74 \\
\hline \multicolumn{2}{|c|}{ Customers' satisfaction with shop-visit experience } & 239 & 1.00 & 5.00 & 3.59 & 0.71 \\
\hline
\end{tabular}

SD, standard deviation.

Table 4. Reliability verification

\begin{tabular}{llcc}
\hline Category & Sub-factors & No. of questions & Cronbach's $\alpha$ \\
& Sense & 5 & 0.858 \\
\multirow{2}{*}{ Drugstore experience factor } & Feel & 5 & 0.886 \\
& Think & 4 & 0.840 \\
& Relate & 4 & 0.878 \\
Customers' satisfaction with shop-visit experience & 4 & 0.796 \\
\hline
\end{tabular}

Table 5. Correlation between drugstore experience factor and customers' satisfaction with shop-visit experience

\begin{tabular}{|c|c|c|c|c|c|c|c|}
\hline \multirow{2}{*}{ Category } & & \multicolumn{5}{|c|}{ Drugstore experience factor } & \multirow{2}{*}{$\begin{array}{l}\text { Satisfaction with shop } \\
\text { visit experience }\end{array}$} \\
\hline & & Sense & Feel & Think & Relate & Act & \\
\hline \multirow{5}{*}{$\begin{array}{l}\text { Drugstore } \\
\text { experience } \\
\text { factor }\end{array}$} & Sense & 1 & & & & & \\
\hline & Feel & $0.554^{* * *}$ & 1 & & & & \\
\hline & Think & $0.598^{* * *}$ & $0.611^{* * *}$ & 1 & & & \\
\hline & Relate & $0.429^{* * *}$ & $0.613^{* * *}$ & $0.599^{* * *}$ & 1 & & \\
\hline & Act & $0.506^{* * *}$ & $0.614^{* * *}$ & $0.665^{* * *}$ & $0.648^{* * *}$ & 1 & \\
\hline \multicolumn{2}{|c|}{$\begin{array}{l}\text { Customers' satisfaction } \\
\text { with shop-visit experience }\end{array}$} & $0.532^{* * *}$ & $0.458^{* * *}$ & $0.558^{* * *}$ & $0.511^{* * *}$ & $0.580^{* * *}$ & 1 \\
\hline
\end{tabular}

The values shown in the table represent $r$ values, i.e., the Pearson correlation coefficient. ${ }^{* * *} p<0.001$.

20 대 여성의 세부 연령은 '만 19 세'가 $52.7 \%$ 로 가장 많았 고, '만 20 세'는 $24.7 \%$, '만 22 세 이상'은 $13.8 \%$, '만 21 세'는 $8.8 \%$ 순이었으며, 한달 평균 저가 브랜드 매장 방문 횟수는 '월 2-3회'가 46.4\%, '월 4-5회'가 22.6\%, '월 1회'가 18.4\%, '월 6 회 이상'이 $12.6 \%$ 순이었다. 매장 방문 시 1 회 평균 구입금액은 '1-5만원 미만'이 65.3\%, '5-10만원 미만'이 15.9\%, '만원 미 만'이 $12.6 \%$, '10만원 이상'이 $6.3 \%$ 순이었으며, 매장 1 회 방문 시 평균 쇼핑 시간은 '10-30 min 미만'이 $60.3 \%$, '10 min 미만' 이 $19.2 \%$, ' $1 \mathrm{~h}$ 이상'이 $10.5 \%$, '30 min-1 h 미만'이 $10.0 \%$ 이
었다. 저가브랜드 매장에서 주로 구매하는 제품은 '색조 화장품 류'가 $32.2 \%$ 로 가장 많았고, '비비크림, 화운데이션류'가 $20.0 \%$, '스킨케어 제품류'가 $14.6 \%$, '액세서리 제품류'가 $11.8 \%$, '기초 화장품류'와 '네일케어 제품류'가 각각 $10.5 \%$, '기타'가 $0.5 \%$ 순 의 분포를 보였다(Table 2).

\section{2. 드럭스토어 체험요인과 매장 방문 경험 만족도}

드럭스토어 체험요인과 매장 방문 경험 만족도 순위는 1순위 브랜드 인지요인 $(\mathrm{M}=3.53)$, 브랜드 감각요인 $(\mathrm{M}=3.52)$, 브랜드 
Table 6. Effects of drugstore experience factors on customers' satisfaction with shop-visit experience

\begin{tabular}{|c|c|c|c|c|c|c|c|}
\hline \multirow{2}{*}{ Category } & & \multicolumn{6}{|c|}{ Dependent variables: customers' satisfaction with testers } \\
\hline & & B & Standard error & $\beta$ & $t$ & $p$ & VIF \\
\hline \multicolumn{2}{|c|}{ Independent variable } & 0.862 & 0.207 & & $4.172^{* * *}$ & 0.000 & \\
\hline \multirow{5}{*}{$\begin{array}{l}\text { Drugstore } \\
\text { experience factor }\end{array}$} & Sense & 0.266 & 0.066 & 0.258 & $-0.016^{* * *}$ & 0.000 & 1.723 \\
\hline & Feel & -0.041 & 0.068 & -0.043 & -0.606 & 0.545 & 2.118 \\
\hline & Think & 0.152 & 0.073 & 0.156 & $2.069^{*}$ & 0.040 & 2.362 \\
\hline & Relate & 0.150 & 0.066 & 0.160 & $2.279^{*}$ & 0.024 & 2.060 \\
\hline & Act & 0.257 & 0.071 & 0.268 & $3.608^{* * *}$ & 0.000 & 2.307 \\
\hline \multicolumn{8}{|c|}{$R^{2}=0.442, \operatorname{adj} R^{2}=0.430, F=36.852^{* * *}$} \\
\hline
\end{tabular}

$\mathrm{R}^{2}$, coefficient of determination; Adj $\mathrm{R}^{2}$, adjusted coefficient of determination; $\mathrm{B}$, unstandardized beta; $\beta$, standardized beta; $t, t$ score; VIF, variance inflation factor; ${ }^{*} p<0.05 ;{ }^{* * *} p<0.001$.

행동요인(M=3.50), 브랜드 관계요인(M=3.27), 브랜드 느낌요인 $(\mathrm{M}=3.26)$ 순으로 체험요인이 높았으며 매장 방문 경험 만족도의 평균은 3.59 로 보통이상으로 높게 나타났다(Table 3 ).

\section{3. 신뢰도 검증}

신뢰도란 동일한 대상, 특성 또는 구성을 비교 가능하고 독자 적인 측정으로 나타난 결과들이 어느 정도 유사한 가를 나타내는 것으로 의존가능성, 안전성, 일관성, 예측가능성, 정확성 등의 동의어로 사용된다. 즉, 신뢰성이란 동일한 개념에 대하여 측정 을 되풀이했을 때 동일한 측정값을 얻을 가능성을 말한다.

신뢰성 측정방법은 동일한 측정도구를 동일한 대상에 시간을 달리하여 적용결과를 비교하는 검증-재 검증, 항목분할 측정치 의 상관도, 내적 일관성 등과 관련된 개념이다. 본 연구에 사용 된 측정도구인 신뢰성은 Cronbach's $\alpha$ 계수를 사용하여 드럭스 토어 체험요인의 평가항목과 만족도의 평가항목 도구가 일관성 있게 측정되었는지 확인하기 위해 신뢰도 분석을 실시하였다. 일 반적으로 사회과학에서 Cronbach's $\alpha$ 값의 기준은 0.6이상 척 도이면 높은 내적 일관성의 단일 차원 구성개념으로 볼 수 있으 므로 본 연구의 신뢰도 분석결과, 최소 0.796 에서 최대 0.903 나타내어 평가 항목의 척도는 내적 일관성을 가지는 단일차원 의 구성개념인 것으로 평가 될 수 있으며 척도들의 신뢰도는 모 두 유의 하다고 할 수 있으며 구체적인 연구 결과는 다음과 같다 (Table 4).

\section{4. 드럭스토어 체험요인이 매장 방문 경험 만족도에 미치는 영향}

드럭스토어 체험요인과 매장 방문 경험 만족도와의 상관관계 연구결과는 다음과 같다. 드럭스토어 체험요인의 브랜드 행동요 인( $\mathrm{r}=0.580, p<0.001)$, 브랜드 인지요인( $\mathrm{r}=0.558, p<0.001)$,
브랜드 감각요인 $(\mathrm{r}=0.532, p\langle 0.001)$, 브랜드 관계요인 $(\mathrm{r}=0.511, p<0.001)$, 브랜드 느낌요인 $(\mathrm{r}=0.458, p<0.001)$ 순 으로 높은 정(+)의 상관관계가 있는 것으로 나타났다(Table 5).

드럭스토어 체험요인을 독립변인으로 하여 각 변인들이 종속 변인인 매장 방문 경험 만족도에 미치는 영향을 알아보기 위하 여 다중회귀분석을 실시한 결과, $\mathrm{R}^{2}=0.442$ 로 나타나 종속변인 인 매장 방문 경험 만족도에 대한 총 변량 중 상기한 5 개의 독립 변수에 의해 설명될 수 있는 총 변량은 $44.2 \%$ 로 회귀모형을 설 명하고 있음을 알 수 있다. 변수간 다중공선성을 진단하기 위 하여 분산팽창계수(variance inflation factor, VIF)와 허용치 (tolerance)를 살펴보았으며, 일반적으로 분산팽창계수가 10이 상이거나 허용치가 0.1 보다 작으면 다중공선성의 문제가 있다 고 판단하게 된다. 본 분석에서 변수들의 VIF값은 모두 10 이 하였고, 허용치는 0.1 보다 크게 나타나 다중공선성의 문제는 발 생하지 않는 것으로 볼 수 있다. 이에 대한 분산분석 결과, 추정 된 모형은 유의한 것을 알 수 있으며 $(F=36.852, p<0.001)$, 드 럭스토어 체험요인의 브랜드 행동요인( $\beta=0.268, p<0.001)$, 브 랜드 감각요인( $\beta=0.258, p<0.001)$, 브랜드 관계요인( $\beta=0.160$, $p\langle 0.05)$, 브랜드 인지요인( $\beta=0.156, p<0.05)$ 순으로 매장 방문 경험 만족도에 유의미한 영향력을 미치는 것으로 나타났다. 따라 서, 드럭스토어 체험요인의 브랜드 행동요인과 브랜드 감각요인, 브랜드 관계요인, 브랜드 인지요인이 높을수록 매장 방문 경험 만족도가 높다는 것을 알 수 있다(Table 6).

\section{Conclusion}

화장품 시장의 새로운 트랜드로 급부상하는 드럭스토어는 단 
순 잡화점이 아닌 토탈 뷰티스토어의 전문숍으로 물건을 구매하 는 행위를 넘어 독특한 체험과 개성으로 인식한다. 그러나 이러 한 트랜드에도 불구하고 한국형 드럭스토어는 약사법에 의한 제 약으로 외국과는 달리 한국형 드럭스토어의 다른 형태로 성장 해 왔다. 한국형 드럭스토어는 제품의 특징이나 기능중심의 전 통적 마케팅이 아닌 제품의 자극이나 교감, 교류를 가질 수 있도 록 하는 체험요인 전략이 활발하게 전개되고 있다. 과거와는 달 리 미용서비스, 마케팅 활용 등이 등장하면서 한 장소에서 원하 는 대부분의 상품을 구입함과 동시에 미용과 건강에 대한 소비자 의 needs까지 확보하는 서비스를 제공한다. 이는 기본적인 제품 의 품질뿐만 아니라 소비자가 지각할 수 있는 경험적 체험 요인 의 요소가 함께 반영되어야 함을 시사한다. 따라서 드럭스토어의 체험요인이 매장 방문 경험 만족도에 미치는 영향을 분석하여 보 다 효율적인 체험요인 제공의 방향성을 찾고자 한다. 이를 위해 국내 드럭스토어를 이용하는 20 대 여성을 대상으로 진행하였으 며 구체적인 실증 분석 결과와 전략적 시사점은 다음과 같다.

첫째, 드럭스토어 체험 요인은 브랜드 인지요인, 감각요인, 행 동요인, 관계요인, 느낌요인의 순으로 높게 나타났으며 매장 방 문 경험 만족도의 평균은 3.59 로 보통이상으로 높게 나타났다. 이러한 결과는 소비자가 드럭스토어 매장을 방문할 때 브랜드에 대한 관심과 흥미, 매장 내 디스플레이 조명등이 매장 방문 경험 만족에 더 영향을 미치는 것으로 인식하고 있음을 의미한다.

둘째, 드럭스토어 체험요인이 브랜드 행동요인( $\beta=0.268$, $p<0.001)$, 브랜드 감각요인( $\beta=0.268, p<0.001)$, 브랜드 관계요 인 $(\beta=0.160, p<0.05)$, 브랜드 인지요인 $(\beta=0.156, p<0.05)$ 순 으로 매장 방문 경험 만족도에 유의미한 영향력을 미치는 것으로 나타났다. 이러한 결과는 체험요인이 드럭스토어 방문 경험 만족 도에 영향을 미치는 것을 알 수 있으며 총체적인 체험요인이 드 럭스토어 만족도에 작용하는 중요한 요소임을 시사한다. 특히 행 동 요인은 매장 방문 경험 만족도에 영향력이 가장 크게 나타난 것으로 보아 소비자가 직접 체험한 후 구매행동으로 미치는 영향 이 더욱 클 것으로 사료된다. 또한 드럭스토어라는 한정된 공간 에서 단순히 제품을 사용해 보는 것뿐만 아니라 디스플레이, 조 명, 향기, 관심, 흥미, 브랜드와의 유대감 제품구매 행동 등으로 체험의 개념적 한계를 극복하고 매장 내 방문 경험의 체험을 즐 김에 따라 매장 방문 경험 만족도가 높아지고 이에 따라 구매행 동에 영향을 미친다는 것을 알 수 있다.

그러나 체험 마케팅 요인만으로는 한국형 드럭스토어 발전에 는 한계가 있으며 한국시장에 맞는 다양성과 전문성을 고려하여 소비자의 요구에 대응 할 수 있는 차별화된 전략이 요구될 것으 로 사료된다. 향후 한국형 드럭스토어의 차별화된 전략을 확보하 기 위해 소비자의 요구를 반영한 총체적인 체험요인의 마케팅 전 략 수립에 기초 자료로 활용되길 기대한다.

본 연구는 드럭스토어의 총체적 체험 요인이 매장 방문 경험에
대한 만족도를 조사하기 위해 주 소비계층인 20대를 연구 대상 으로 선정하였으나 향후 연구에서는 표본의 특성을 소비층에 대 한 세분화와 제품별 체험요인에 대한 만족도를 비교하여 일반화 된 연구 결과를 도출할 수 있을 것으로 사료된다.

\section{Acknowledgements}

This paper is funded by the 2017 Research Funds of Suwon Women's University.

\section{References}

Choi SB, Lee KS, Han TY. The relationships of satisfaction, tour place loyalty of eastcoast ocean leisure sports participants experience based on strategic experiential modules. The Korean Society of Sports Science, 22: 8797, 2013.

Cho YM, Kim GS, Kang SO. An effect of the preference of the cosmetics advertisement model on brand assets and purchase intention: focusing on consumption type. Asian Journal of Beauty and Cosmetology, 13: 167-177, 2015.

Hwang J, Lee JM. The effect which cosmetic brand shop experience marketing makes on brand satisfaction, attachment and loyalty. Jounal of the Korean Society of Cosmetology, 17: 1086-1096, 2011.

Kim MJ, Lee HR, Chae MS. The influence of drugstore environment on perceived overall atmosphere, emotion, and revisiting intentions. Journal of Channel and Retailing, 20: 1-22, 2015.

Lee JM, Hwang JS. The effect of experiential marketing on the brand equity of low-priced cosmetics brands. Journal of the Korean Society of Costume, 60: 100-117, 2010.

Lee KE, Han HR. Spatial composition of drugstore applied with experience marketing for sales promotion: focused on the health \& beauty stores around the Hong-ik university. Korean Institute of Interior Design Journal, 23: 193-203, 2014.

Lee KY, Han HR. A study on spatial composition of drugstore applied of experience marketing: focused on health \& beauty stores in Hongdae. Korean Institute of Interior Design Journal, 2013: 133-138, 2013.

Lee SY. A study on brand image, customer satisfaction and purchase intention in domestic health \& beauty store. 
Journal of the Korean Society Design Culture, 22: 333346, $2016 a$.

Lee SY. A study on the state and brand differentiation strategies of Korean-style drug stores. Journal of the Korean Society of Design Culture, 22: 443-456, $2016 \mathrm{~b}$.

Lee SE. Effects of low-price cosmetics experience factors on satisfaction with test products. Asian Journal of Beauty and Cosmetology, 14: 417-425, $2016 \mathrm{c}$.

Park SY. A study on the current state of drugstore and the necessity of regulation. Journal of Asia Trade and Business, 1: 1-14, 2014.

Park G, Chung K. A study on characteristics of consumers in the Korean drug store context: focused on lifestyle, ICT ability, repurchase intent. The Journal of Internet
Electronic Commerce Research, 15: 179-203, 2015.

Suh $\mathrm{CH}$. A study on the influence of the experiential factors of local festivals on the perceived values, satisfaction, and behavior intention of tourists. Journal of The Korean Data Analysis Society, 14: 435-450, 2012.

Yang GS, Jo EJ. The structural relationship between perceived value, quality of life, and experience: an example from tourists at a Korean tea museum. International Journal of Tourism and Hospitality Research, 30: 17-30, 2016.

Yoon SM, Lee TH. Effect relationship of the experience on emotion and satisfaction in theme park: focused on the perspective of experiential marketing. Journal of Tourism and Leisure Research, 24: 289-308, 2012. 


\section{국문초록}

\section{드럭스토어 체험 요인이 매장 방문 경험 만족도에 미치는 영향}

이상은

수원여자대학교 미용예술과, 경기도 수원시, 한국

목적: 본 연구는 변화되고 있는 뷰티시장의 형태를 반영한 한국형 드럭스토어가 제공하는 환경적 자극에 대해 실무적 체험요인이 매장 방문 경험 만족도에 미치는 영향관계를 규명하고자 한다. 방법: 드럭스토어 방문 경험이 있는 20대 여성을 대상으로 편의 표 집하였다. 만족도의 신뢰도는 Cronbach's $\alpha$ 계수로 판단하였고, 드럭스토어 체험요인이 매장 방문 경험 만족도에 미치는 영향을 알 아보기 위하여 상관분석과 다중회귀분석을 실시하였다. 결과: 드럭스토어 체험 요인과 매장 방문 경험 만족도와의 상관관계는 브 랜드 행동요인, 인지요인, 감각요인, 관계요인, 느낌요인 순으로 높은 상관관계가 있는 것으로 나타났다. 브랜드 행동요인과 브랜드 감각요인, 브랜드 관계요인, 브랜드 인지요인이 높을수록 매장 방문 경험 만족도가 높은 것으로 나타났다. 결론: 체험요인이 드럭 스토어 방문 경험 만족도에 영향을 미치는 것을 알 수 있으며 총체적인 체험요인이 만족도에 작용하는 중요한 요소임을 시사한다. 특히 행동 요인은 매장 방문 경험 만족도에 영향력이 가장 크게 나타난 것으로 보아 소비자가 직접 체험한 후 구매행동으로 미치는 영향이 더욱 클 것으로 사료된다.

핵심어: 체험요인, 드럭스토어, 화장품 산업, 만족도, 체험 마케팅

This paper is funded by the 2017 Research Funds of Suwon Women's University.

\section{참고문헌}

김미정, 이혜리, 채명수. 드럭스토어의 점포 환경이 소비자가 인식하는 총체적인 분위기와 감정 및 재방문의도에 미치는 영향. 유통연구, 20: 1-22, 2015.

박귀정, 정기한. 한국형 드럭 스토어의 소비자 특성 연구: 라이프스타일, ICT 활용도, 재구매의도를 중심으로. 인터넷전자 상거래연구, 15: 179-203, 2015.

박선영. 국내 드럭스토어의 현황 및 규제 필요성 연구. 아시아무역연구, 1: 1-14, 2014.

서철현. 지역축제의 체험요인이 관광객의 지각된 가치와 만족도 및 행동의도에 미치는 영향. 한국자료분석학회지, 14 : 435-450, 2012.

양길승, 조은주. 체험요인에 따른 지각가치와 삶의 질과의 구조 관계: 보성 한국차박물관 관광객을 대상으로. 관광연구저

널, 30: 17-30, 2016.

윤설민, 이태희. 테마파크에서의 체험이 감정과 만족도에 미치는 영향관계: 체험마케팅 관점을 중심으로. 관광레저연구, 24: 289-308, 2012.

이경은, 한혜련. 체험마케팅을 적용한 드럭스토어의 공간구성에 관한 연구: 홍대헬스 \& 뷰티숍을 중심으로. 한국실내디자 인학회 학술대회논문집, 2013: 133-138, 2013.

이경은, 한혜련. 판매촉진을 위한 체험마케팅이 적용된 드럭스토어 공간구성: 홍대앞 $\mathrm{H \& B}$ 스토어를 중심으로. 한국실내 디자인학회 논문집, 23: 193-203, 2014.

이상은. 저가화장품 체험 요인이 테스터 제품 사용만족도에 미치는 영향. 아시안뷰티화장품학술지, 14: 417-425, 2016c.

이승영. 국내 헬스 \& 뷰티스토어의 브랜드 이미지 및 고객만족 구매의도에 관한 연구. 한국디자인문화학회지, $22: 333-$ $346,2016 \mathrm{a}$. 
이승영. 한국형 드럭스토어의 현황 및 브랜드 차별화 전략에 관한 연구. 한국디자인문화학회지, $22: 443-456,2016 \mathrm{~b}$.

이정민, 황진숙. 저가 화장품 브랜드 체험 제공수단과 체험 마케팅 유형이 브랜드자산에 미치는 영향. 복식, 60: 100117, 2010.

조윤민, 김계숙, 강식옥. 화장품 광고모델 호감도가 브랜드 자산과 구매의도에 미치는 영향: 소비유형을 중심으로. 아시안 뷰티화장품학술지, 13: 167-177, 2015.

최성범, 이계석, 한태용. 체험마케팅(SEMs)에 근거한 동해안의 해양레저스포츠체험이 만족 및 관광지 충성도에 미치는 영 향. 한국체육과학회지, 22: 87-97, 2013.

황진숙, 이정민. 화장품 브랜드숍에서의 체험마케팅 유형이 브랜드 만족, 애착 및 충성도 형성에 미치는 영향. 한국미용학 회지, 17: 1086-1096, 2011. 


\section{中文摘要}

\section{Drugstore体验因素对顾客访店经验满意度的影响}

李相恩

水原女子大学美容艺术科，京畿道水原市，韩国

目的: 本研究调查了关于反映美容市场状况变化的韩国Drugstore所提供的环境刺激, 药店体验因素对顾客访 问店铺经验满意度的影响关系。方法: 对20多岁曾到过Drugstore的女性进行了便利抽样。克朗巴赫的 $\alpha$ 系数 （Cronbach's a) 决定了满意度的可靠性。此外, 还进行了相关分析和多元回归分析, 以调查Drugstore体验因 素对顾客访店经验满意度的影响。结果：关于Drugstore体验因素与顾客访问经验的满意度之间的相关性，可以 按照高度相关性依次排列以下因素 : 品牌行为因素、思考因素、感觉因素、关系因素和感受因素。发现品牌行 为因素, 品牌感知因素, 品牌关系因素和品牌意识因素越高, 顾客对访店经验的满意度越高。结论: 这项研究 结果表明, Drugstore体验因素影响顾客访店经验的满意度, 整体体验因素是满意度的重要因素。特别是, 行 为因素对顾客对其购物体验的满意度影响最大, 这表明消费者亲自体验后, 会对他们的购买行为产生更大的影 响。

关键词: 体验因素, Drugstore, 化妆品产业, 满意度, 体验营销 